\title{
Trajectory and Determinant of Functional Independence among Patient with Traumatic and Non-Traumatic Spinal Cord Injury
}

\author{
Yudha Mathan Sakti ${ }^{1}$, Astri Ferdiana ${ }^{2}$, Dananjaya Putramega ${ }^{3}$, Zikrina A. Lanodiyu ${ }^{4}$, \\ Galih Prasetya Sakadewa ${ }^{5}$, Rahadyan Magetsari ${ }^{6}$ \\ 1,3,4,5,6 Department of Orthopaedics and Traumatology, Faculty of Medicine, Universitas Gadjah Mada, Dr. Sardjito \\ General Hospital, Yogyakarta, Indonesia \\ ${ }^{2}$ Department of Public Health, Faculty of Medicine, Universitas Gadjah Mada, Yogyakarta, Indonesia
}

\begin{tabular}{l}
\hline Article Info \\
\hline Article history: \\
Received May 16, 2018 \\
Revised Jun 6, 2018 \\
Accepted Jun 8, 2018 \\
\hline
\end{tabular}

\section{Keyword:}

Functional independence measurement

Quality of life

Spinal cord injury

\begin{abstract}
The level of functional independence was directly proportional to life satisfaction and quality of life in patients with spinal cord injury. By knowing the determinants that predict changes in functional independence, medical treatment and rehabilitation can be better planned to improve the patient's quality of life. We conducted a prospective cohort study on 49 patients with spinal cord injury at Dr. Sardjito general hospital Yogyakarta from April to June 2016. The data were taken before patient underwent surgery, before discharged from the hospital, and 3 months after underwent surgery. We found that most common spinal cord injury was at the level of lumbar vertebra with 28 patients $(58 \%)$. There was a positive trajectory of the patients with spinal cord injury with ASIA grade B-E classification. However, patients with spinal cord injury with ASIA classification grade A have a neutral trajectory.We conclude there was a positive trajectory between functional independence and traumatic or non-traumatic spinal cord injury except in patients with ASIA grade A classification spinal cord injury. The determinants that affected the trajectory of patients with spinal cord injury were the level of the injured vertebra and severity of the neurological deficit.
\end{abstract}

Copyright $(9) 2018$ Institute of Advanced Engineering and Science. All rights reserved.

\section{Corresponding Author:}

Zikrina A. Lanodiyu,

Department of Orthopaedics and Traumatology Dr. Sardjito General Hospital

Kesehatan No 1 Sekip Yogyakarta, Indonesia.

Email: zikrina.lanodiyu158@gmail.com

\section{INTRODUCTION}

A spinal cord injury can cause severe physical disability because it can lead to decreased or loss of motor and sensory functions beneath the lesion. Most spinal cord injury patients cannot move or feel any sensory stimuli beneath the lesion. This spinal cord injury is caused by traumatic or non-traumatic injury [1].

The incidence of spinal cord injury is lower than the other type of injury [2]. However, the health, social, and economic problems caused by the disability from spinal cord injury are quite severe. The social and economic burden resulting from the loss of productivity and high and long-term rehabilitation costs from spinal cord injury can greatly burden the patient, family members, and government [3]. The disability caused by spinal cord injury also associated with psychological disorders such as depression [4] and decreased the quality of life [5]. Numerous studies showing that the quality of life in patients with spinal cord injury is lower than healthy populations or patient with chronic diseases [6-8]. Factors affecting patient with spinal cord injury include: 1) Sociodemographic and economic characteristic; 2) severity of the spinal cord injury; 3) disease onset and age when the injury occurred; 4) psychosocial condition; 5) any comorbidities such as urinary tract infection; 6) mobility and assistive devices; 7) physical capacity and functional independence [8-10]. 
Several previous studies have shown that the level of functional independence was directly proportional to life satisfaction and quality of life in patients with spinal cord injury. Functional independence is the key to the ability to perform daily activities and participation in the community [11]. To the present day, there is no therapy that can achieve total recovery in patients with spinal cord injuries. Therefore, the goals of medical intervention including surgical intervention and rehabilitation is to optimize the functional independence so as to increase mobilization, activities of daily living (ADL), and prevent complications such as decubitus ulcer, so that the patient's quality of life can increase. Without proper treatment, spinal cord injuries can be a significant health problem in Indonesia. Moreover, with the high rate of accidents as well as the increase in the population with older age, the incidence of spinal cord injury in Indonesia was quite large. Earlier research has studied the determinants affection functional independence [12-13]. Nevertheless, these studies are mostly conducted in developed countries. In many developing countries like Indonesia, very limited data was available on spinal cord injuries. In addition, most studies of functional independence in spinal cord injuries use cross-sectional research design, in which the trends in functional independence from before surgery to several months after the patient returns home cannot be observed, and the causal relationship between the determinant and the functional independence as output cannot be enforced.

The trajectory trends of functional independence in patients with spinal cord injuries undergoing surgery should be identified to assess and predict postoperative progress. By knowing the determinants that predict changes in functional independence, medical treatment and rehabilitation can be better planned. The aim of this study was to know the trajectory of functional independence in patients with spinal cord injuries and the determinants that can be used to predict the trajectory of functional independence.

\section{RESEARCH METHOD}

Ethical clearance had been approved by the Medical and Health Research Ethics committee (MHREC) Faculty of Medicine Gadjah Mada University with the reference number KE/FK/015/EC/2017. We then performed a prospective cohort study on 49 patients with spinal cord injury at Dr. Sardjito general hospital Yogyakarta from April to June 2016. The patients were recruited using the consecutive sampling method with the following criteria: over 15 years of age, diagnosed with traumatic or non-traumatic spinal cord injury, not suffering from any mental disorder, agreed to underwent surgery by the orthopaedic surgeon in Dr. Sardjito General Hospital, and agreed to be the participant of this study.

The variable taken in this study were Sociodemographic characteristics (age, sex, occupancy, educational status, income, and health financing program), Quality of life (measured before underwent surgery, before discharged from the hospital, and 3 months after the surgery using World Health Organization Quality of Life (WHOQoL) questionnaire that was validated into Bahasa Indonesia), Physical examination (Etiology of the injury, classified into traumatic and non-traumatic based on the primary diagnosis), Characterization of the neurological impairment using the International Standards for Neurological Classification of Spinal Cord Injury Classification. The neurological impairment classified as paraplegia and tetraplegia; the severity of the injury classified using American Spinal Injury Association Impairment Scale (AIS Scale). AIS grade A as complete motor impairment, whereas AIS grade B, C, and D classified as incomplete motor impairment; Any comorbidities or complications such as decubitus ulcer, urinary tract infection, pain and others complications; Type of the surgery: instrumentation (implant installation) and non-instrumentation (decompression without implant installation); Functional Independence was measured using Functional Independence Measure (FIM) instrument consisting of 13 items that include self-care, mobility, and etc. FIM is an instrument that has been used to assess the functional independence in patients with spinal cord injury [13].

The measurement was conducted by the research assistant; who is a general practitioner that has been trained in this research method before the patient underwent surgery (baseline), before discharged from the hospital, and 3 months after underwent surgery. The discharge criteria were general status (good vital signs, no signs of bleeding, normal leukocyte counts and no signs of infection) and local status (good-looking surgical wound, drain product less than $10 \mathrm{cc} / 24$ hours). The third measurement was done at 3 months after discharge from the hospital. Data collection includes structured interviews and physical examination by physicians who have been trained on techniques and methods related to this study.

Trajectory analysis will be performed with latent class growth models analysis. As the pattern emerges from the data, the trajectory of functional independence will be classified into three categories: Negative Trajectory, Neutral Trajectory, or Positive Trajectory. Bivariate and multivariate multinomial regression analysis was performed to identify sociodemographic and clinical determinants that predict positive trajectory. Further analysis was conducted to determine the relationship between the trajectory of functional independence and the quality of life. 


\section{RESULT AND ANALYSIS}

There were a total of 49 patients (34 men and 15 women) eligible for this study. As mentioned in Table 1, patients with spinal cord injuries at the level of lumbar vertebra were 28 patients (58\%), thoracal vertebra were 13 patients (26\%), and cervical vertebra were 8 patients (16\%). The average age of the participants was 48.3 . There were 32 participants with age more than 40 years $(66 \%)$, and 17 participants with age less than 40 years (34\%). ASIA score classification of ASIA score A were 21 patients (44\%), ASIA score B was 1 patient (2\%), ASIA score C were 6 patients (12\%), ASIA score D were 10 patients (20\%), and ASIA score E were 11 patients (22\%).

This result is similar with previous studies [15], Male patients were more dominant than female patients in spinal cord injuries. Demographic characteristics and injury-related characteristics were associated with individual-level trajectories reflecting life satisfaction.Table 1 shows demographic characteristics include race, sex, pre-employment and marital status, and level education. Injury related characteristics include neurologic level, age at injury, and injury etiology [21].

Table 1. Sociodemographic Characteristic

\begin{tabular}{|c|c|c|}
\hline \multicolumn{2}{|c|}{ Variables } & \multirow{2}{*}{$\begin{array}{l}\text { Total } \\
34(72 \%)\end{array}$} \\
\hline Sex & Male & \\
\hline & Female & $15(28 \%)$ \\
\hline \multirow[t]{3}{*}{ Vertebra Level } & Lumbal & $28(58 \%)$ \\
\hline & Thoracal & $13(26 \%)$ \\
\hline & Cervical & $8(16 \%)$ \\
\hline \multirow[t]{2}{*}{ Age } & $>40$ years & $36(73,5 \%)$ \\
\hline & $<40$ years & $13(26,5 \%)$ \\
\hline \multirow[t]{5}{*}{ ASIA Score } & A & $21(44 \%)$ \\
\hline & B & $1(2 \%)$ \\
\hline & $\mathrm{C}$ & $6(12 \%)$ \\
\hline & $\mathrm{D}$ & $10(20 \%)$ \\
\hline & E & $11(22 \%)$ \\
\hline
\end{tabular}

\subsection{Trajectory by Age Group and Gender}

The average FIM as shown in Table 2 of the participants with age <40 years was 96.6 and participant with age $>40$ years was 96.8 . The average FIM of the participants at 3 months after the surgery with age $<40$ years was 102.7 and participant with age $>40$ years was 102.6. The average FIM of male participants was 95.4 and a female participant was 99.6. At 3 months after surgery, the average FIM in the male participants was 100.6 and in female participants were 107.

Table 2. Trajectory by Age group and Gender

\begin{tabular}{lcccc}
\hline & & FIM before surgery & FIM at discharge & FIM 3 months after surgery \\
\hline Age & & & & \\
$<40$ years & 12 & $96.6( \pm 11.6)$ & $96.6( \pm 11.6)$ & $102.7( \pm 13.5)$ \\
$>40$ years & 37 & $96.8( \pm 5.9)$ & $96.8( \pm 5.9)$ & $102.6( \pm 7.2)$ \\
Sex & & & & \\
Male & 34 & $95.4( \pm 6.3)$ & $95.4( \pm 6.3)$ & $100.6( \pm 7.6)$ \\
Female & 15 & $99.6( \pm 9.5)$ & $99.6( \pm 9.5)$ & $107( \pm 11.4)$ \\
\hline
\end{tabular}

This study showed that there was a positive trajectory on the male and female group. There was also a positive trajectory in the $<40$ years of age group and $>40$ years of age group. Dahlberg showed that there was no significant difference based on sex and age with functional independence in patients with spinal cord injury [14].

\subsection{Trajectory Based on the Injured Vertebra Level}

The average FIM of participants with spinal cord injury at the level of vertebra thoracal was 90.08 , vertebra lumbal was 101.54, and vertebra cervical was 89. The average FIM at 3 months after surgery at the level of vertebra thoracal was 93.92, at the level of vertebra lumbal was 19.69, and at the level of vertebra cervical was 93.44 shown in Table 3 . Table 3 informs that there was a positive trajectory of FIM in the patients with spinal cord injury at the level of vertebra cervical, thoracal, and lumbar at 3 months after surgery compared to the FIM before the surgery. Cohen and Kemal also said that there was an increase in the functional independence of patients with spinal cord injury at the level of vertebra cervical, thoracal, or lumbar [16-17]. Patients with spinal cord injury at the level of vertebra cervical have lower functional 
outcome than patients with spinal cord injury at the level of vertebra thoracal or lumbar at 3 months after surgery $(\mathrm{p}<0,05)$. Dahlberg also said that patients with spinal cord injury at the level of vertebra cervical have lower functional outcome than patients with spinal cord injury at another vertebra level [14].

Table 3. FIM Based on the Injured Vertebra Level

\begin{tabular}{llcccc}
\hline \multirow{2}{*}{ FIM before surgery } & $\mathrm{N}$ & Mean & Std. Deviation & Std. Error \\
& Thoracal & 13 & 90.08 & 17.675 & 4.902 \\
& Lumbal & 28 & 101.54 & 17.536 & 3.314 \\
& Cervical & 9 & 89 & 15.716 & 5.239 \\
FIM at discharge & Total & 50 & 96.3 & 17.945 & 2.538 \\
& Thoracal & 13 & 90.08 & 17.675 & 4.902 \\
& Lumbal & 28 & 101.54 & 17.536 & 3.314 \\
& Cervical & 9 & 89 & 15.716 & 5.239 \\
& Total & 50 & 96.3 & 17.945 & 2.538 \\
& & & & \\
FIM at 3 months after surgery & Thoracal & 13 & 93.32 & 22.119 & 6.135 \\
& Lumbal & 28 & 108.68 & 20.342 & 3.844 \\
& Cervical & 9 & 93.44 & 19.514 & 6.505 \\
& Total & 50 & 102.1 & 21.592 & 3.504 \\
\hline
\end{tabular}

\subsection{Trajectory Based on the ASIA Classification}

From this study, we found the average FIM in participants with spinal cord injury with the ASIA grade A classification was 75.81, the ASIA grade B classification was 76, the ASIA grade C classification was 82.3, the ASIA grade D classification was 95, and the ASIA grade E classification was 113.6 shown in Table 4. The FIM at 3 months after surgery the ASIA grade A classification was 77.36, the ASIA grade B classification was 76, the ASIA grade C classification was 85.1, the ASIA grade D classification was 101.6, and the ASIA grade E classification was 122.5 .

Table 4. FIM Based on the ASIA Classification

\begin{tabular}{llllll}
\hline & & $\mathrm{N}$ & Mean & Std. Deviation & Std. Error \\
\hline FIM before surgery & $\mathrm{A}$ & 11 & 75.81 & 1.6 & 0.48 \\
& $\mathrm{~B}$ & 1 & 76 & & 0 \\
& $\mathrm{C}$ & 6 & 82.3 & 4.17 & 1.7 \\
& $\mathrm{D}$ & 10 & 95 & 10.43 & 3.29 \\
FIM at discharge & $\mathrm{E}$ & 21 & 113.6 & 9.27 & 2.02 \\
& $\mathrm{~A}$ & 11 & 75.81 & 1.6 & 0.48 \\
& $\mathrm{~B}$ & 1 & 76 & & 0 \\
FIM at 3 months after surgery & $\mathrm{C}$ & 6 & 82.3 & 4.17 & 1.7 \\
& $\mathrm{D}$ & 10 & 95 & 10.43 & 3.29 \\
& $\mathrm{E}$ & 21 & 113.6 & 9.27 & 2.02 \\
& $\mathrm{~A}$ & 11 & 77.36 & 3.38 & 1.02 \\
& $\mathrm{~B}$ & 1 & 76 & & 0 \\
& $\mathrm{C}$ & 6 & 85.1 & 3.25 & 1.32 \\
& $\mathrm{D}$ & 10 & 101.6 & 14.5 & 4.6 \\
& $\mathrm{E}$ & 21 & 122.5 & 10.4 & 2.29 \\
\hline
\end{tabular}

The average FIM of participants with the ASIA grade D-E classification before the surgery was 107.61, and participants with the ASIA grade A-C was 77.84. The average FIM of participants with the ASIA grade D-E classification at 3 months after surgery was 115.81, and participants with the ASIA grade A-C was 79.74.

There was a positive trajectory of the patients with spinal cord injury with ASIA grade B-E classification. However, patients with spinal cord injury with ASIA classification grade A have a neutral trajectory. This finding was appropriate with other studies that spinal cord injuries with ASIA grade D and E classification have better functional outcome than spinal cord injury with ASIA classification grade A-C [14, 18-19].

\subsection{Correlation Between FIM and Quality of Life}

The result of pearson correlation can be seen in Table 5. It shows that FIM have positive correlation with physical fitness $r=0.716 p<0.05$, limitation due to physical $r=0.506 p<0.05$, limitation due to emotional $\mathrm{r}=0.506 \mathrm{p}<0.05$, energy level $\mathrm{r}=0.736 \mathrm{p}<0.05$, emotional well-being $\mathrm{r}=0.635 \mathrm{p}<0.05$, social interaction $\mathrm{r}=0.689 \mathrm{p}<0.05$, pain $\mathrm{r}=0.238 \mathrm{p}<0.05$, and general health $\mathrm{r}=0.406 \mathrm{p}<0.05$ 
Table 5. FIM Pearson Correlation

\begin{tabular}{|c|c|c|c|c|c|c|c|c|c|c|}
\hline & & FIM & $\begin{array}{c}\text { Physical } \\
\text { Fitness }\end{array}$ & $\begin{array}{l}\text { Limitation } \\
\text { due to } \\
\text { physical }\end{array}$ & $\begin{array}{l}\text { Limitation } \\
\text { due to } \\
\text { emotional }\end{array}$ & $\begin{array}{c}\text { Energy } \\
\text { level }\end{array}$ & $\begin{array}{c}\text { Emotional } \\
\text { well } \\
\text { being }\end{array}$ & $\begin{array}{c}\text { Social } \\
\text { interaction }\end{array}$ & Pain & $\begin{array}{c}\text { General } \\
\text { health }\end{array}$ \\
\hline \multirow[t]{2}{*}{ FIM } & $\mathrm{r}$ & 1 & & & & & & & & \\
\hline & $\begin{array}{l}\text { Sig. (2- } \\
\text { tailed) }\end{array}$ & & & & & & & & & \\
\hline Physical & $\mathrm{r}$ & $.716^{* * *}$ & 1 & & & & & & & \\
\hline Limitation & $\mathrm{r}$ & $.506^{* * *}$ & $.680 * *$ & 1 & & & & & & \\
\hline $\begin{array}{l}\text { due to } \\
\text { physical }\end{array}$ & $\begin{array}{l}\text { Sig. (2- } \\
\text { tailed) }\end{array}$ & .000 & .000 & & & & & & & \\
\hline Limitation & $\mathrm{r}$ & $.506^{* * *}$ & $.680 * *$ & $1.000 * *$ & 1 & & & & & \\
\hline $\begin{array}{l}\text { due to } \\
\text { emotional }\end{array}$ & $\begin{array}{l}\text { Sig. (2- } \\
\text { tailed) }\end{array}$ & .000 & .000 & .000 & & & & & & \\
\hline Emotional & $\mathrm{r}$ & $.635^{* *}$ & $.644 * *$ & $.613 * *$ & $.613 * *$ & $.907 * *$ & 1 & & & \\
\hline well being & $\begin{array}{l}\text { Sig. (2- } \\
\text { tailed) }\end{array}$ & .000 & .000 & .000 & .000 & .000 & & & & \\
\hline Social & $\mathrm{r}$ & $.689 * *$ & $.541 * *$ & $.280 * *$ & $.280 * *$ & $.588^{* *}$ & $.527 * *$ & 1 & & \\
\hline Interaction & $\begin{array}{l}\text { Sig. (2- } \\
\text { tailed) }\end{array}$ & .000 & .000 & .001 & .001 & .000 & .000 & & & \\
\hline \multirow[t]{2}{*}{ Pain } & $\mathrm{r}$ & $.238 * *$ & $.306^{* *}$ & $.504 * *$ & $.504 * *$ & $.521 * *$ & $.592 * *$ & $.205^{* *}$ & 1 & \\
\hline & $\begin{array}{l}\text { Sig. (2- } \\
\text { tailed) }\end{array}$ & .003 & .000 & .000 & .000 & .000 & .000 & 0.012 & & \\
\hline General & $\mathrm{r}$ & $.406^{* *}$ & $.461 * *$ & $.664 * *$ & $.664 * *$ & $.676^{* *}$ & $.687 * *$ & $.367 * *$ & $.834 * *$ & 1 \\
\hline Health & $\begin{array}{l}\text { Sig. (2- } \\
\text { tailed) }\end{array}$ & .000 & .000 & .000 & .000 & .000 & .000 & .000 & .000 & \\
\hline
\end{tabular}

This result showed that psychosocial factors and clinical factors act as an important factor in predicting the Quality of life in patients with spinal cord injuries [15]. Various levels of functioning (physical, social, and psychologic), perception of health, life satisfaction, and demographic factors were also found to be predictive of or associative with quality of life in people with spinal cord injury [22]. Pervious study also showed that people with SCI were able to maintain quality of life and participation in life, but the trajectory of quality of life remained relatively flat [20].

\section{CONCLUSION}

This study showed that there was a positive trajectory between functional independence and traumatic or non-traumatic spinal cord injury except in patients with ASIA grade A classification spinal cord injury. The determinants that affected the trajectory of patients with spinal cord/ injury were the level of the injured vertebra and severity of the neurological deficit.

\section{REFERENCES}

[1] World Health Organization \& The International Spinal Cord Injury Society, International Perspectives on Spinal Cord Injury, 2013.

[2] Chen, A. Y, \& Colantonio, A., "Defining neurotrauma in administrative data using the International Classification of Diseases Tenth Revision", Emerg Themes Epidemiol, 4, 8, 2011.

[3] Cobley, D. S., "Towards economic participation: examining the impact of the Convention on the Rights of Persons with Disabilities in India" Disabil Soc 28, 441-455, 2013.

[4] Williams, R. \& Murray, A., "Prevalence of depression after spinal cord injury: a meta-analysis", Arch Phys Med Rehabil 96, 133-40, 2015.

[5] Post, M. W. M. \& van Leeuwen, C. M. C., "Psychosocial issues in spinal cord injury: a review", Spinal Cord 50, 382-9, 2012.

[6] Geyh, S. et al., "Quality of life after spinal cord injury: a comparison across six countries", Spinal Cord 51, 322-6, 2013.

[7] $\mathrm{Ku}, \mathrm{J}$., "Health-related quality of life in patients with spinal cord injury: review of the Short Form 36 Health Questionnaire Survey", Yonsei Med J 48, 360-370, 2007.

[8] Post, M. \& Noreau, L., "Quality of life after spinal cord injury", J Neurol Phys Ther 29, 139-46, 2005.

Trajectory and Determinant of Functional Independence in Patient with Traumatic... (Yudha Mathan Sakti) 
[9] Dijkers, M., "Quality of life of individuals with spinal cord injury: A review of conceptualization, measurement, and research findings", J Rehabil Res Dev 42, 87, 2005.

[10] Leduc, B. E. \& Lepage, Y., "Health-related quality of life after spinal cord injury", Disabil Rehabil 24, 196-202, 2002.

[11] Wood-Dauphinée, S. et al., "Quality of life in patients with spinal cord injury--basic issues, assessment, and recommendations", Restor Neurol Neurosci 20, 135-49, 2002.

[12] Jongjit, J., Sutharom, W., Komsopapong, L. \& Numpechitra, N., "Functional independence and rehabilitation outcome in traumatic spinal cord injury", Southeast Asian J Trop Med Public Health 35, 2004.

[13] Hall, K. M., Cohen, M. E., Wright, J., Call, M. \& Peter Werner., "Characteristics of the Functional Independence Measure in traumatic spinal cord injury”, Arch Phys Med Rehabil 80, 1471-1476, 1999.

[14] Dahlberg, A., Kotila, M., Kautiainen, H., Alaranta, H., "Functional independence in persons with spinal cord injury in Helsinki”, J Rehabil Med., Sep;35(5):217-20, 2003.

[15] Ekechukwu, END. Ikrechero, JO. Ezukwu, AO. Egwuonwu, AV. Umar, L. Badaru, UM., "Determinants of Quality of Life Among Community-Dewlling Persons with Spinal Cord Injury: A Path Analysis", Niger J CLin PRact 201720163-9.

[16] Cohen, JT., Marino, RJ., Sacco, P., Terrin, N., "Association between the Functional Independence Measure following spinal cord injury and long-term outcomes", Spinal Cord 50,728-733, 2012.

[17] Kemal, N, Levent, Y, Volkan, S, Abdulkadir, A., and Kadriye, Ö., "Rehabilitation of spinal cord injuries", World J Orthop, Jan 18; 6(1): 8-16, 2015.

[18] Geyh, S., et al., "Quality of life after spinal cord injury: a comparison across six countries", Spinal Cord 51, 322-6, 2013.

[19] Hall, K. M., Cohen, M. E., Wright, J., Call, M. \& Peter Werner., "Characteristics of the Functional Independence Measure in traumatic spinal cord injury", Arch Phys Med Rehabil 80, 1471-1476, 1999.

[20] Pershouse KJ, Barker RN, Kendall MB, Buettner PG, Kuipers P, Schuurs SB, Amsters DI., "Investigating changes in quality of life and function along the lifespan for people with spinal cord injury", Arch Phys Med Rehabil 93:413-9, 2012

[21] Pretz CR, Kozlowski AJ, Chen Y, Charlifue S, Heinemann AW., "Trajectories of Life Satisfaction After Spinal Cord Injury", Arch Phys Med Rehabil 97:1706-13 2016.

[22] Tate DG, Kalpakjian CZ, Forchheimer MB., "Quality of life issues in individuals with spinal cord injury", Arch Phys Med Rehabil 83 Suppl 2:S18-25, 2001. 